\title{
A population estimate of Heaviside's dolphins, Cephalorhynchus heavisidii, at the southern end of their range
}

\author{
Simon H. Elwen * Desray Reeb $\uparrow$ Meredith Thornton $\$$ Peter B. Best $\$$
}

* Mammal Research Institute, University of Pretoria, Iziko South African Museum,

P. O. Box 61, Cape Town, 8000, South Africa

E-mail: simon.elwen@gmail.com

$\dagger$ Mammal Research Institute, University of Pretoria, Iziko South African Museum, P. O. Box 61, Cape Town, 8000, South Africa and 52-65th Place, Long Beach, California 90803, U.S.A.

\$ Mammal Research Institute, University of Pretoria, Iziko South African Museum, P. O. Box 61, Cape Town, 8000, South Africa

\section{Abstract}

Heaviside's dolphins, Cephalorhynchus heavisidii, are endemic to southwestern Africa, where they are exposed to unknown levels of anthropogenic threats, including inshore set netting. Using photo-ID data collected over $3 \mathrm{yr}$ on the west coast of South Africa, we calculated Chapman's-modified Petersen estimates of the number of distinctive individuals at three spatial scales. Sample sizes were small and recapture rates low resulting in high variance. Total population abundance was extrapolated from the proportion of well-marked animals in the population $(14 \%-17 \%)$ with between-year estimates adjusted for mortality using data from Commerson's dolphin. The total population size was calculated as 527 animals $(\mathrm{CV}=0.35$, CI 272-1,020) in the 1999 study area (20 km of coastline, within season), 3,429 animals (CV $=0.36$, CI 1,721$6,828)$ in the central study area $(150 \mathrm{~km}$ of coastline, $3 \mathrm{yr})$, and 6,345 animals $(\mathrm{CV}=$ 0.26 , CI 3,573-11,267) in the full study area (390 km of coastline, $2 \mathrm{yr}$ ). Dolphins fitted with satellite transmitters varied in their use of the inshore photographic study area from $39.5 \%$ to $94.7 \%$ of transmission days (38-51 total). Given the known or suspected biases in the data, these abundance estimates are likely to be biased downward.

\section{Article text}

Heaviside's dolphins are coastal delphinids that range along the west coast of southern Africa. Their coastal distribution brings them into contact with potential anthropogenic impacts including directed and incidental (by)catch, pollution, and vessel disturbance, of which the most severe is likely to be bycatch (Best and Abernethy 1994). Populations of congeneric species with similar coastal distributions have been severely impacted by 
nearshore fishing activities (Dawson 1991, Iñíguez et al. 2003). Although the coastline along which Heaviside's dolphins occur is relatively sparsely populated, there is an unquantified but potentially high source of bycatch in an inshore set net fishery for St Joseph's shark (Callorhinchus capensis) in the St Helena Bay area. General knowledge of this species remains poor and data are urgently needed to be able to fully assess the threats to this population; foremost among these is knowledge of the size of the population.

Capture-mark-recapture (CMR) techniques are particularly appropriate for assessing populations where the degree of individual risk within a given area is of concern, as they provide an estimate of the number of animals using an area over a series of sampling periods, even if not all those animals are in the area at all times (Seber 1982). In this study, abundance estimates have been calculated from resightings of photographically identified Heaviside's dolphins at spatial scales that are relevant to management. The central study area (155 km alongshore) overlapped almost exactly with a single consolidated management unit used by Marine and Coastal Management (Department of Environmental Affairs and Tourism, South Africa) to control the inshore subsistence fisheries, including those thought to present a potentially significant bycatch threat. The 20-km-long core study area near Britannia Bay is a relevant management scale for boat-based dolphin watching as well as small area developments such as harbor development (a potential issue at Sandy Point adjacent to the east of this region).

Within the overall range of the species (west coast of Africa from $16^{\circ}$ to $34^{\circ} \mathrm{S}$ ), the distribution of Heaviside's dolphins is apparently continuous (Findlay et al. 1992) although with areas of higher and lower density associated mainly with overall prey abundance (Elwen 2008). Individual animals show site fidelity to particular areas $(<80$ $\mathrm{km}$ alongshore) and their home ranges overlap extensively (Elwen et al. 2006). Although Heaviside's dolphins are found concentrated near the breakers in the morning where they are apparently resting (Elwen 2008), they disperse several kilometers offshore in the afternoon (Elwen et al. 2006) to feed on demersal prey, predominantly juvenile hake (Merluccius spp.) (Sekiguchi 1994). When moving offshore, animals become more evasive and are correspondingly more difficult to photograph (personal observation). This diurnal pattern to the movement and "catchability" of dolphins has implications for photographic mark-recapture studies since animals are potentially not always available for recapture. We use the telemetry data of Elwen et al. (2006) to investigate how the "true" movements of individuals compare with and potentially affect the results from the photographic mark-recapture since the low number of resightings observed in this study seems at odds with the evidence of high site fidelity observed from satellite telemetry (Elwen et al. 2006) and photo-ID data (Elwen 2008). The majority of Heaviside's dolphins lack the natural dorsal fin markings required for individual identification (Lockyer and Morris 1990). Therefore, the extrapolation from the estimated number of identifiable (marked) animals to the total population size is greater than in most other delphinid studies (e.g., Wilson et al. 1999, Parra et al. 2005, Heinrich 2006), stressing the importance of determining the percentage of marked animals in the population $(\theta)$ as accurately as possible. In this study, we investigate 
variations in $\theta$ with area and examine potential photographer bias toward more distinctively marked animals by comparing estimates of $\theta$ from photographs with those recorded in the field by photographers.

\section{Methods}

\section{Field Techniques}

Data were collected over the summer months of 1999-2001 along the west coast of South Africa south of $c a .31^{\circ} 50^{\prime} \mathrm{S}$, approximately the southernmost one-seventh of the species' known range. During the first year of the study 6 wk of effort (26 sea days) was expended over a $20-\mathrm{km}$ section of coast (Fig. 1), the core study area, in an attempt to photographically identify all the animals using that area. In years 2 and 3 of the study (39 and 44 sea days, respectively), we searched the full $390 \mathrm{~km}$ of our study area launching from six different harbors and searching coastwise in an attempt to recapture the animals identified in year 1; as a result, our effort was spatially broad, but relatively limited temporally and in most areas did not cover more than 2 wk of effort each year.

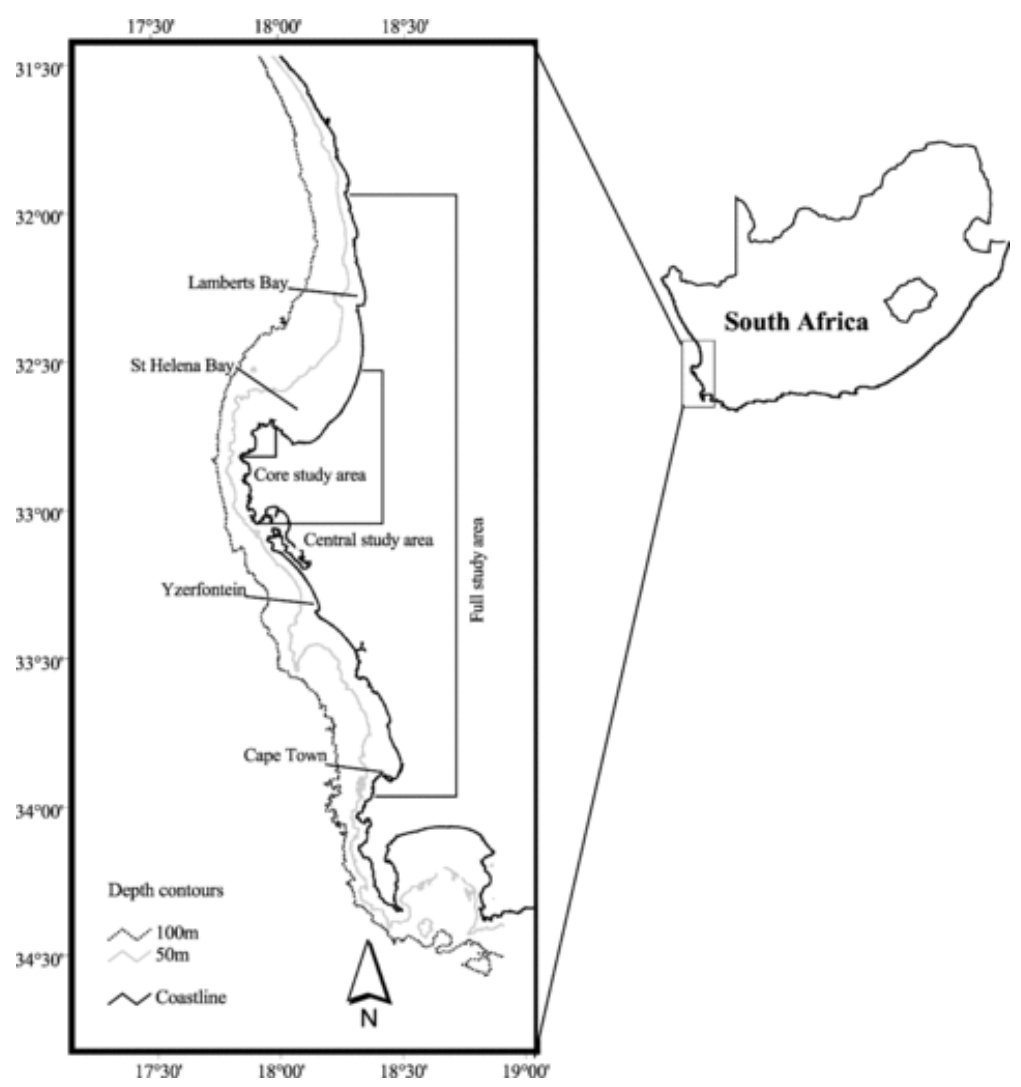

Figure 1. Map of study area showing three spatial scales at which abundance estimates of Heaviside's dolphins were calculated; the full study area from 2000 to 2001, the central study area for 1999-2001, and the 1999 core study area.

All data were collected from a 6-m RIB with twin 40-hp 2-stroke outboards and an 
elevated observation platform (putting eyes at $3 \mathrm{~m}$ above the sea level). Daily search areas were dependent on previously searched areas and on prevailing winds, and were undertaken coastwise just behind the breaker line at a speed of 6-8 kn. All dolphins were followed until photography of the group was regarded as complete or until the dolphins were lost. Photography was with manual focus Nikon F301 and Minolta F300s cameras using Kodak T-Max 400 film; in 1999 only one photographer was used, but in 2000 and 2001 two photographers took pictures from opposite sides of the boat. An effort was made to photograph all animals in the group whether marked or unmarked, but after each encounter in 2000 and 2001 both photographers independently recorded their estimate of how many "marked" animals were seen in the group and how many they had photographed. To reduce repeat photography of boat-friendly dolphins, the boat would speed up after photography to $12-15 \mathrm{kn}$ in an attempt to lose them.

\section{Laboratory Techniques}

Negatives were examined for quality and distinctiveness using a variable magnificationdissecting microscope (up to $32 \times$ magnification) over a light table. Photographs were rated for quality $(\mathrm{Q})$ : 1 = barely identifiable; 2 = very poor; $3=$ contains information, but is not good; 4 = can make out small marks but edges not perfectly clear; 5 = good; 6 $=$ excellent (big, focused, well lit, perpendicular to camera). Animals were rated for distinctiveness (D): 1 = no mark; 2 = small single notch/marking; 3 = two or more marks of reasonable size/fairly unique marking; 4 = several, obvious markings, unique shapes; $5=$ extremely obvious mutilations. These latter determinations were based on as many photos as possible to minimize the relationship between photographic quality and ability to observe distinctiveness (Read et al. 2003, Friday et al. 2000). Both rating systems were subjective, but the ratings were checked several times by a single observer to maintain consistency. In general, markings tended to be small and relegated to the trailing edge; shape and coloring were not usable and scarring was deemed to be not useful for long-term matching. Only photos of $Q \geq 4$ and animals of $D \geq 3$ were used for mark-recapture analyses. Marked fins of usable quality were scanned into digital format and compared on screen to the existing catalogue: if a match was not found, animals were given a unique number and added to the catalogue. It was not considered feasible to relax these criteria any further without compromising the reliability of the results.

\section{Analysis: Mark-Recapture Estimates}

The number of recognizable individuals within the study area was calculated using a series of Chapman's-modified Petersen (CMP) estimates. This estimator assumes that all individuals have an equal probability of being captured in the first sample, that the second sample is random and there is complete mixing of the population between samples, that marking does not affect the catchability of the animal, that marks do not change between samples and are correctly reported upon sighting, and that there are no births, deaths, emigrations or immigrations between samples (Seber 1982).

Abundance estimates were calculated at three different scales. A two sample inter-year 
estimate of the number of animals using the full study area from Cape Town to Lamberts Bay $\left(31^{\circ} 50^{\prime}-34^{\circ} 00^{\prime} \mathrm{S}\right)$ used the geographically comparable data collected in 2000 and 2001. Two inter-year estimates (1999-2000 and 2000-2001) were calculated for the central section of our study area $\left(32^{\circ} 30^{\prime}-33^{\circ} 04^{\prime} \mathrm{S}\right)$. These were considered likely to be more robust than the estimate for the full coast as the majority of the data over the three years of the study $(50 \%)$ were collected in this central section. Biologically these estimates might be more appropriate as the area is roughly one home range to the north and south of the 1999 core study area (Elwen et al. 2006), and more practically it is equivalent to the fisheries management unit for the St Helena Bay area. Lastly, three estimates for the core area in $1999\left(32^{\circ} 45^{\prime} \mathrm{S}-32^{\circ} 49^{\prime} \mathrm{S}\right)$ were calculated using the three 2wk field trips as separate samples, all of which were close enough in time to be unaffected by issues of mortality and mark loss.

The abundance of well-marked animals $\widehat{N}$ for all three scales was calculated using the Chapman's modified Petersen estimate: $\hat{N}=\frac{\left(n_{1}+1\right)\left(n_{2}+1\right)}{m_{2}+1}-1$ (1)where $n_{1}=$ number of well-marked animals identified in the first sample $n_{2}=$ number of well-marked animals identified in the second sample $m_{2}=$ number of well-marked animals identified in both samples.

Variance for the estimate is calculated as

$$
\operatorname{var}(\widehat{N})=\frac{\left(n_{1}+1\right)\left(n_{2}+1\right)\left(n_{1}-m_{2}\right)\left(n_{2}-m_{2}\right)}{\left(m_{2}+1\right)^{2}\left(m_{2}+2\right)} .
$$

As unmarked animals are not included in either $n_{1}$ or $n_{2}$, the estimate applies only to well-marked animals.

\section{Analysis: Meeting Assumptions of Mark-Recapture Analysis}

Violating the assumptions of mark-recapture analyses can greatly affect both the accuracy and precision of the results (Hammond 1986). Fin mutilations and injuries in cetaceans are generally regarded as permanent (Lockyer and Morris 1990), so mark loss per se is not an issue, but it is possible for marks to alter to the point where a previously identified animal becomes unrecognizable (Gowans and Whitehead 2001). A combination of using only well-marked animals and good quality photographs, and a relatively short study period $(800 \mathrm{~d})$ in which marks are unlikely to have changed much, reduces the chances of misidentification errors in this study.

It is unlikely that the assumption of equal capture probability of all individuals is ever truly upheld by a natural population due to underlying variability at the individual level (Hammond 1986, Durban and Elston 2005). Such variation may be apparent as attraction toward the boat for bowriding or an avoidance of the boat by, for instance, mothers with calves. Further, Heaviside's dolphins show high site fidelity to small home ranges, so for any given location animals may have ranges entirely overlapping the study area or barely touching it, in which case their probabilities of being resighted are likely to differ. Thus, only geographically equivalent areas have been used for calculations at different scales. If the assumption of equal capture probability is violated, it will result in an underestimated population size (Hammond 1986). Due to 
the nature of our data (broadly spread along the coast and with a low resighting rate) it was not possible to attempt to account for capture heterogeneity using modeling techniques for which a large sample size and multiple recapture occasions are required (White et al. 1982). The most effective way to minimize heterogeneity is to maximize the capture rate so that there is little chance that any individual is undetected. ${ }^{1}$ Due to this study's primary focus on dispersal, the low mark rate of Heaviside's dolphins and the large population, sample sizes were not big enough to allow for an effective analytical approach to account for heterogeneity. Nevertheless, satellite telemetry data were used to investigate the likelihood of spatial heterogeneity of capture probabilities (see below).

CMP estimates assume demographic (no births or deaths) and population (no emigration and immigration) closure. Given the small home ranges (considerably smaller than the full study area) and high site fidelity of the species, mark-recapture data collected within a set area should deal with a "closed" set of animals, thereby reasonably approximating the assumption of geographic closure.

When demographic turnover occurs, the resulting population estimate tends to be overestimated by roughly the inverse of the survival rate (Hammond 1986). Although mortality in multi-year studies of large whales has been effectively ignored due to their high survival rate (Stevick et al. 2001), it is likely to have a larger effect in short-lived species such as Cephalorhynchus dolphins. No estimates for the survival or birth rates of Heaviside's dolphins are available, but since the influence of mortality is a known error, including a less accurate correction factor is better than applying none. As the well-marked animals were most likely adults, the survival rate of 0.914 (0.01 SD) for adult (5-18 yr) Commerson's dolphins (Lockyer et al. 1988) has been used. No a priori reason existed to expect an increasing or decreasing population, so recruitment to the marked population is assumed to be equal to losses from mortality.

\section{Analysis: Estimating the Percentage of Marked Animals $(\theta)$ in the Population}

To investigate possible biases in the estimate of $\theta$, we compared the values calculated from well-marked animals in good quality photographs $\left(\theta_{1}\right)$ to those estimated in the field by photographers, using the proportion of marked animals seen $\left(\theta_{2}\right)$ and the number thought to have been photographed $\left(\theta_{3}\right)$. Data for both photographers were combined for values of $\theta_{2}$ and $\theta_{3}$. Values of $\theta_{1}$ were compared for each of the 2 -wk field trips worked in different parts of the study area using at least 100 randomly selected good quality images for each trip. To determine which measure of $\theta$ is most accurate we compared how the three rates varied with the group size. The standard measure of $\theta_{1}$, the "percentage of good quality images containing distinctively marked fins" could not be used, as it was not possible to effectively differentiate by group size. Instead we used "percentage identified of seen" referred to as $\theta_{1}$ (theta-one-prime), or the percentage of distinctive animals finally identified and catalogued of the total number of animals seen in the field in that group size category. This value $\left(\theta_{1^{\prime}}\right)$ is thus lower than the proportion of marked animals calculated only from good quality photos as all those groups seen in the field which were not well photographed, or contained no marked animals, have been 
included in the denominator. Several confounding factors may affect this analysis; the "time per dolphin" of a sighting decreases as the group size increases, smaller groups (one or two animals) tend to be more evasive than larger groups making them more difficult to approach and photograph (Elwen 2008) and very large groups of dolphins usually consisted of several subgroups that might arrive at or leave the boat at slightly different times and move around and mix, making it more difficult to get full photographic coverage.

\section{Analysis: Estimating the Total Population Size}

Because estimates of $\theta$ varied both spatially and temporally, only photographs taken during the relevant field trips were used to calculate $\theta_{1}$ for each abundance estimate. For each estimate, the average value and error were calculated from 50 random samples of 100 good images (or 50 images for the smaller 1999 data set) taken from the total set of good quality images $(n=1,071,835$, and 396 for the full study area, central study area and 1999 study area, respectively). Where more than one estimate was available for a spatial scale, the inverse $\mathrm{CV}$-weighted average of the population size was used and subsequently adjusted using the $0.914(0.01 \mathrm{SD})$ correction for mortality where appropriate.

The total population size was calculated as $N_{\text {stal }}=\frac{\widehat{N}}{\theta}$ with the variance calculated by the delta method (Wilson et al. 1999): $\quad\left(\overline{\hat{N}^{2}}+\frac{1-\theta}{n \hat{\theta}^{2}}\right)$ where $n$ is the total number of dorsal fins from which $\theta$ was calculated. $\mathrm{CV}$ for the total population expressed as terms of the CVs of the CMP estimate and $\theta$ :

$C V\left(\hat{N}_{a t}\right)=\sqrt{(C V(\hat{N}))^{2}+(C V(\hat{\theta}))^{2}} \cdot$ The log-normal confidence interval (recommended by Burnham et al. (1987) to avoid an unrealistic lower confidence interval below zero)

was calculated using the formula:

$$
r=\exp \left(1.96 \sqrt{\ln \left(1+\left(\mathrm{CV}\left(N_{\text {add }}\right)\right)^{2}\right)}\right) \text { with the lower }
$$

confidence interval calculated as $N / r$ and the upper limit as $N^{*} r$.

\section{Comparison Between Satellite and Field Observations}

The telemetry data from five female Heaviside's dolphins (Elwen et al. 2006) were used to analyze the proportion of time for which these individuals were potentially available for photographic capture. We present the number of received locations in total for each tag, as well as those received in "daylight" (defined as 0700-1600 to be roughly equivalent to boat-based photo-ID work), and those daylight locations in the inshore study area searched for dolphins (within $2 \mathrm{~km}$ from shore). These locations are not independent within a day as they were received with high frequency (every $2 \mathrm{~h}$ ), so the data have been summarized to a daily level to represent the number of days in which the animals were potentially available for photographic capture using the 1999-2001 field protocol. 


\section{Results}

\section{CMP Estimates of the Number of Well-marked Individuals}

The discovery curve of new animals identified per survey (Fig. 2) increases approximately linearly during each sampling period with little sign of the curve flattening out, indicating that only a small proportion of the population was captured. Consequently, there is generally a low recapture rate $\left(m_{2}\right.$ in Equation 1$)$, which translates into a larger variance in the abundance estimates (Equation 2, Table 1).

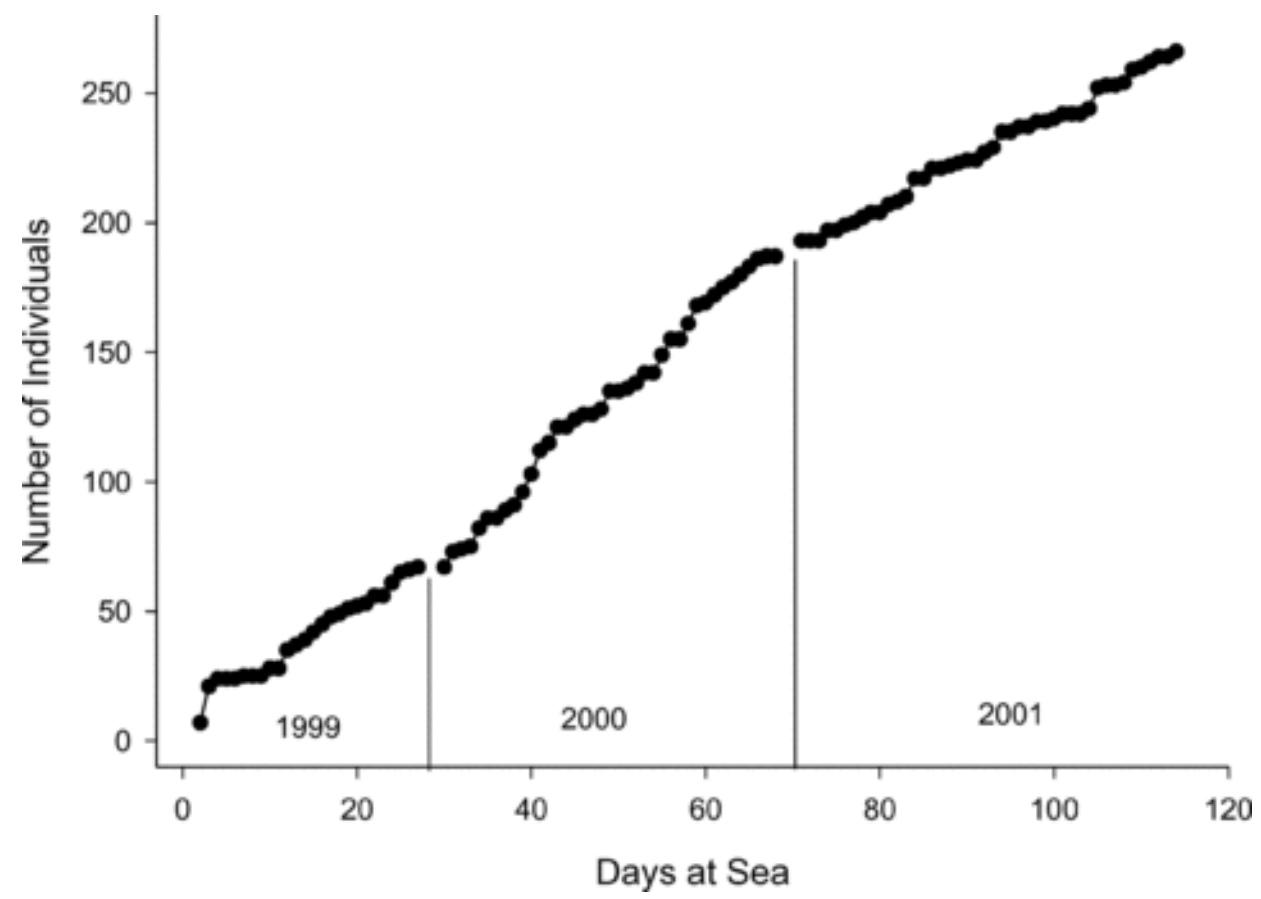

Figure 2 . Discovery curve (number of new animals discovered per survey day) for well-marked Heaviside's dolphins photographed off South Africa in 1999, 2000, and 2001. 
Table 1. Chapman's-modified Petersen estimates (unadjusted for inter-year mortality) of the population size of well-marked Heaviside's dolphins $(N)$, with standard deviations, $\mathrm{CVs}$ and $95 \%$ log-normal confidence intervals for each estimate. Calculations shown for the three scales (1) full coast (390 km, $2 \mathrm{yr}),(2)$ central area only (150 km, $3 \mathrm{yr})$, and (3) 1999 study area (20 km, three 2-wk sampling trips) and averaged using the inverse $\mathrm{CV}$-weighted mean. Inter-year estimates not adjusted for mortality of marked individuals.

\begin{tabular}{|c|c|c|c|c|c|c|c|c|}
\hline Area & Period & $n_{1}$ & $n_{2}$ & $m_{2}$ & $\hat{N}$ & SD $(\widehat{N})$ & $\mathbf{C V}(\hat{N})$ & $95 \%$ CI \\
\hline Full coast & $2000-2001$ & 120 & 99 & 11 & 1,007 & 248.9 & 0.25 & 625,1623 \\
\hline \multirow[t]{3}{*}{ Central area } & $1999-2000$ & 67 & 34 & 3 & 594 & 242.95 & 0.41 & 275,1284 \\
\hline & $2000-2001$ & 34 & 53 & 3 & 472 & 191.36 & 0.41 & 219,1013 \\
\hline & Inv $\mathrm{CV}$ mean & & & & 532 & 154.35 & 0.29 & 305,929 \\
\hline \multirow[t]{4}{*}{1999 area } & $1-2$ & 26 & 26 & 3 & 181 & 69.43 & 0.38 & 88,374 \\
\hline & $2-3$ & 26 & 35 & 5 & 161 & 49.29 & 0.31 & 78,333 \\
\hline & $1-3$ & 26 & 35 & 14 & 64 & 8.25 & 0.13 & 31,132 \\
\hline & Inv $\mathrm{CV}$ mean & & & & 87 & 11.15 & 0.13 & 68,112 \\
\hline
\end{tabular}

CMP estimates of the number of well-marked Heaviside's dolphins off the southern west coast of South Africa, uncorrected for mortality, are presented in Table 1 for three spatial scales. Two estimates for 1999 are very similar but the third is considerably smaller, due to a higher number of resightings that occurred between these samples.

\section{Investigations of $\theta$-the Mark Rate of Animals}

The three estimates of $\theta$ were compared for each 2-wk sampling trip and although the three values of $\theta$ were closely correlated $\left(\theta_{1}-\theta_{2}: r^{2}=0.747 ; \theta_{1}-\theta_{3}, r^{2}=0.847\right.$, both significant at the $5 \%$ level), in seven out of eight cases $\theta$ was higher when measured from photographs than from field estimates (Table 2). Possible explanations for this pattern include a bias toward photographing marked animals or groups containing marked animals more extensively, thereby inflating the estimate of $\theta$. Conversely, the inability of the photographers to detect small marks on small fast moving animals that did not always come very close to the boat may have resulted in underestimates of $\theta_{2}$ and $\theta_{3}$. 
Table 2 . Estimated percentages of well-marked Heaviside's dolphins $(\theta)$ by area [St Helena Bay (StH), Cape Town (CT), Yzerfontein (YZ), Lamberts Bay (LB)] and by field trip $(\mathrm{a}, \mathrm{b}, \mathrm{c}) . \theta_{1}=\%$ of good quality fin images containing well marked animals $(n=$ the number of photos from which $\theta_{1}$ was calculated), $\theta_{2}=\%$ of marked animals seen, and $\theta_{3}=\%$ of marked animals thought to have been photographed in the field.

\begin{tabular}{llllll} 
Period & $\boldsymbol{n}$ & Area & \multicolumn{1}{c}{$\boldsymbol{\theta}_{\mathbf{1}^{\prime}}$} & $\boldsymbol{\theta}_{\mathbf{2}}$ & $\boldsymbol{\theta}_{\mathbf{3}}$ \\
$1999 \mathrm{a}$ & 100 & StH & 25 & - & - \\
$1999 \mathrm{~b}$ & 102 & StH & 14.7 & - & - \\
1999 c & 194 & StH & 12.9 & - & - \\
1999 all & 396 & & 16.41 & & \\
2000 & 105 & CT & 23.8 & 17.0 & 14.1 \\
2000 & 129 & YZ & 18.6 & 16.4 & 11.9 \\
2000 & 141 & LB & 16.3 & 14.9 & 11.2 \\
2000 & 145 & StH & 11.0 & 9.8 & 8.5 \\
2000 all & 519 & & 16.76 & 14.2 & 11.1 \\
2001 & 115 & LB & 8.7 & 8.5 & 7.2 \\
2001 & 131 & StH & 18.3 & 10.7 & 9.1 \\
2001 & 163 & StH & 7.9 & 8.0 & 6.8 \\
2001 & 108 & YZ & 16.67 & 11.5 & 9.8 \\
2001 & $35^{\mathrm{a}}$ & CT & $34.28^{\mathrm{a}}$ & 14.8 & 13.6 \\
2001 all & 534 & & 13.29 & 9.8 & 8.4 \\
& & & & & \\
\hline
\end{tabular}

${ }^{\mathrm{a}}$ Only one day was worked out of Cape Town harbor in 2001.

The highest proportions of marked animals were recorded in groups of 3-5 and 1-2 animals in 2000 and 2001, respectively (Fig. 3). A decreasing $\theta$ with increasing group size is seen in both years and may have been caused by a reduced ability to detect and photograph all marked animals in large groups, or the pattern may be a result of a variation in social structure with group size, such as the higher proportion of calves observed in larger groups. However, due to the high turnover of group membership (Elwen 2008) and the low percentage of calves overall (3.6\%) the decrease is more likely to be due to inefficiency of capture than to a social effect. This inefficiency is also reflected in the photographic coverage of groups since $\theta_{1^{\prime}}$ shows a general reduction with increasing group size and the ratio between $\theta_{2}$ (those seen) and $\theta_{3}$ (those thought to have been photographed) increases with increasing group size. It can be concluded that there was likely a degree of underreporting of marked animals in the field and a decreased efficiency of capture with the increasing group size. We thus consider the value of $\theta$ calculated from photographs $\left(\theta_{1}\right)$ to be the most representative measure available. Any bias by photographers in the field toward focusing on marked animals is likely to act in the opposite direction to any inefficiency. 


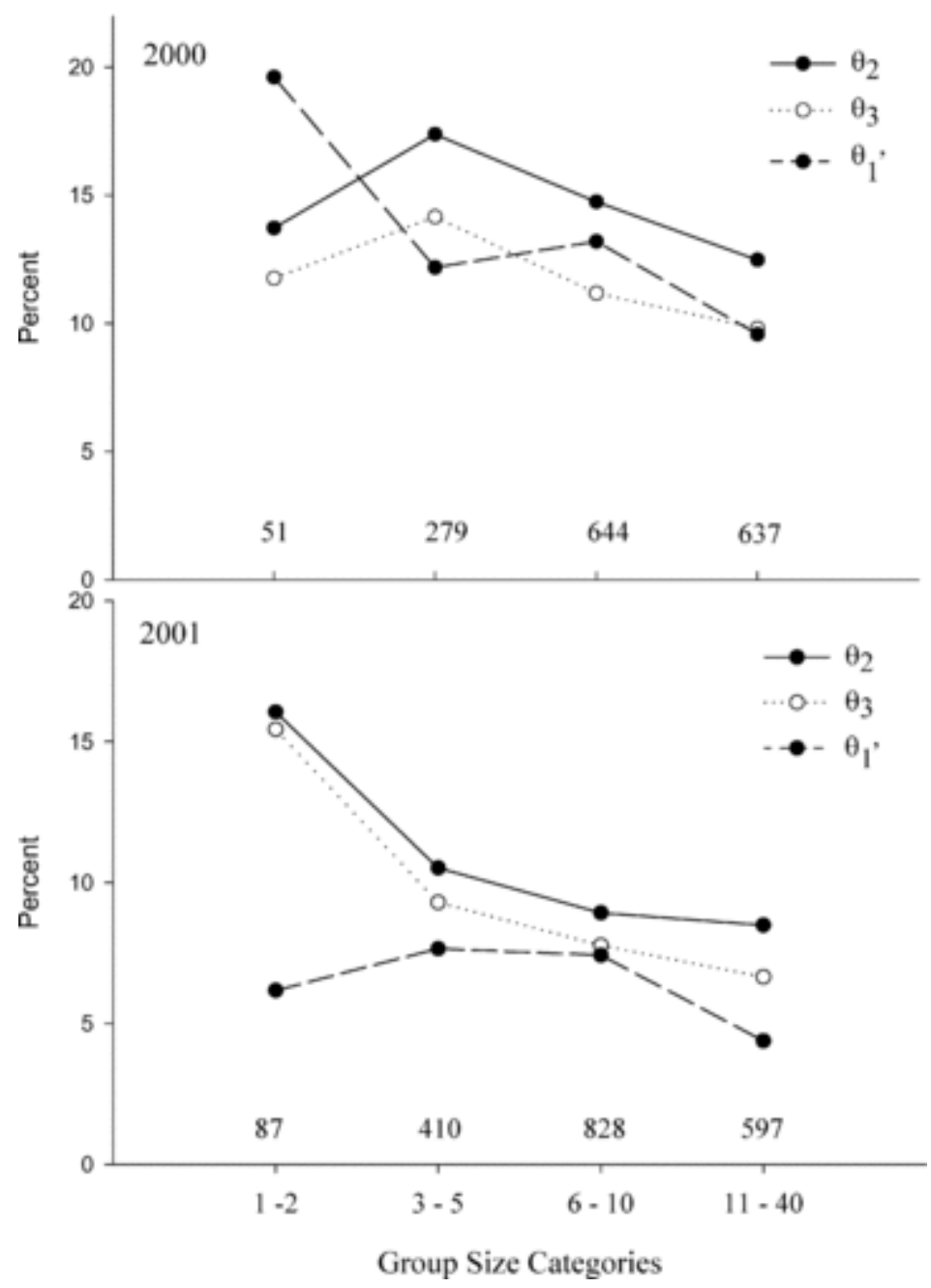

Figure 3 . Variation in three different measures of the mark rate of Heaviside's dolphins with observed group size, 2000 and 2001. $\theta_{1}=\%$ of good quality fin images containing well marked animals, $\theta_{2}=\%$ of marked animals seen, and $\theta_{3}=\%$ of marked animals thought to have been photographed in the field. Values under points are the number of animals seen in that group size category.

The proportion of marked animals (all measures) varied with location, generally decreasing with distance northwards from Cape Town (Table 2) and with season, being lower in 2001 than in 2000. The highest mark rate, from Cape Town in 2001, needs to be treated with caution as only one day was worked in the area in this year. This aside, the geographic pattern is consistent between years, but with only two samples from each location we must be cautious in interpreting these patterns. The multiple measures in St Helena Bay show considerable variation even between trips within the same year, suggesting that there is considerable stochasticity in the measure of $\theta$. Therefore, $\theta_{1}$ was calculated separately for each abundance estimate using only data from the relevant area and time periods. Total extrapolated population estimates for each spatial scale are given (Table 3) for both the simple and the mortality corrected estimates. 
Table 3 . Estimates of total population size $\left(N_{\text {tot }}\right)$ for Heaviside's dolphins at three different spatial scales.

\begin{tabular}{|c|c|c|c|c|c|c|c|c|}
\hline \multirow[b]{2}{*}{ Area } & \multirow[b]{2}{*}{$\boldsymbol{\theta}_{1}$} & \multirow{2}{*}{$\begin{array}{l}\mathbf{C V} \\
\boldsymbol{\theta}_{1^{\prime}}\end{array}$} & \multicolumn{3}{|c|}{$\begin{array}{l}\text { No mortality } \\
\text { correction }\end{array}$} & \multicolumn{3}{|c|}{ Mortality corrected } \\
\hline & & & $N_{\text {tot }}$ & CV & $95 \%$ CI & $N_{\text {tot }}$ & $\mathrm{CV}$ & $95 \% \mathrm{CI}$ \\
\hline $\begin{array}{l}\text { Full coast } \\
2000-2001\end{array}$ & 14.51 & 0.23 & 6,942 & 0.24 & $\begin{array}{l}3,989 \\
12,082\end{array}$ & 6,345 & 0.26 & $\begin{array}{l}3,573 \\
11,267\end{array}$ \\
\hline $\begin{array}{l}\text { Central area } \\
(1999-2001) \\
\text { Inv CV mean }\end{array}$ & 14.19 & 0.27 & 3,751 & 0.29 & $\begin{array}{l}1,920 \\
7,326\end{array}$ & 3,429 & 0.36 & $\begin{array}{l}1,721 \\
6,828\end{array}$ \\
\hline $\begin{array}{l}1999 \text { Area Inv } \\
\text { CV mean }\end{array}$ & 16.62 & 0.37 & 527 & 0.35 & $\begin{array}{l}272 \\
1,020\end{array}$ & $\mathrm{n} / \mathrm{a}$ & & \\
\hline
\end{tabular}

$N_{\text {tot }}$ extrapolated from Chapman's modified Petersen estimates of the number of marked animals $(\hat{N})$ using the proportion of well-marked animals in the population $\left(\theta_{1}\right)$. Inter-year estimates corrected for mortality of marked animals using the survival rate $(0.914, \mathrm{SD}=0.01)$ of adult Commerson's dolphins (Lockyer et al. 1988).

\section{Interpretations of Relevant Satellite Tag Data}

The transmitter life on the satellite tagged females in 2004 (up to $51 \mathrm{~d}$ ) was similar in duration to the 1999 field season (52 d) and occurred in the same area (St Helena Bay), making it an appropriate comparison, albeit with a 5-yr time lag and the caveat that there were no telemetry data from male dolphins. The breakdown of satellite locations clearly shows that the five tagged dolphins varied considerably in the amount of time they were potentially available for photography, i.e., within $2 \mathrm{~km}$ from shore and during daylight hours (Table 4). These periods tended to be clumped over several days (Fig. 4) and at least one animal (Dolphin 5) spent more time in the unsurveyed offshore environment than inshore. 
Table 4. The number of locations received from satellite-tagged Heaviside's dolphins while they were potentially available to be photographed using the techniques in this study, defined as being within $2 \mathrm{~km}$ from the shore and in daylight hours (0700-1600).

\begin{tabular}{|c|c|c|c|c|c|c|}
\hline $\begin{array}{l}\text { Tag } \\
\text { identity }\end{array}$ & $\begin{array}{l}\text { Total no. } \\
\text { locations }\end{array}$ & $\begin{array}{l}\text { No. } \\
\text { daylight } \\
\text { locations }\end{array}$ & $\begin{array}{l}\text { No. } \\
\text { daylight } \\
\text { locations } \\
\text { in survey } \\
\text { area }\end{array}$ & $\begin{array}{l}\% \\
\text { daylight } \\
\text { locations } \\
\text { in survey } \\
\text { area }\end{array}$ & $\begin{array}{l}\text { Days in } \\
\text { survey } \\
\text { area in } \\
\text { daylight } \\
\text { (total tag- } \\
\text { life }^{\mathrm{a}} \text { ) }\end{array}$ & $\begin{array}{l}\% \text { days of } \\
\text { tag-life in } \\
\text { survey } \\
\text { area in } \\
\text { daylight }\end{array}$ \\
\hline $\begin{array}{l}\text { Dolphin } \\
1\end{array}$ & 428 & 165 & 66 & 40 & $23(41)$ & 56.1 \\
\hline $\begin{array}{l}\text { Dolphin } \\
2\end{array}$ & 313 & 116 & 40 & 34.5 & $27(42)$ & 64.3 \\
\hline $\begin{array}{l}\text { Dolphin } \\
3\end{array}$ & 578 & 207 & 100 & 48.3 & $36(51)$ & 70.6 \\
\hline $\begin{array}{l}\text { Dolphin } \\
4\end{array}$ & 490 & 171 & 124 & 72.5 & $36(38)$ & 94.7 \\
\hline $\begin{array}{l}\text { Dolphin } \\
5\end{array}$ & 693 & 233 & 51 & 21.8 & $17(43)$ & 39.5 \\
\hline
\end{tabular}

${ }^{\mathrm{a}}$ Excluding the initial $72-120 \mathrm{~h}$ after tagging when dolphin behavior was considered to be potentially affected by the capture and tagging process (Elwen et al. 2006).

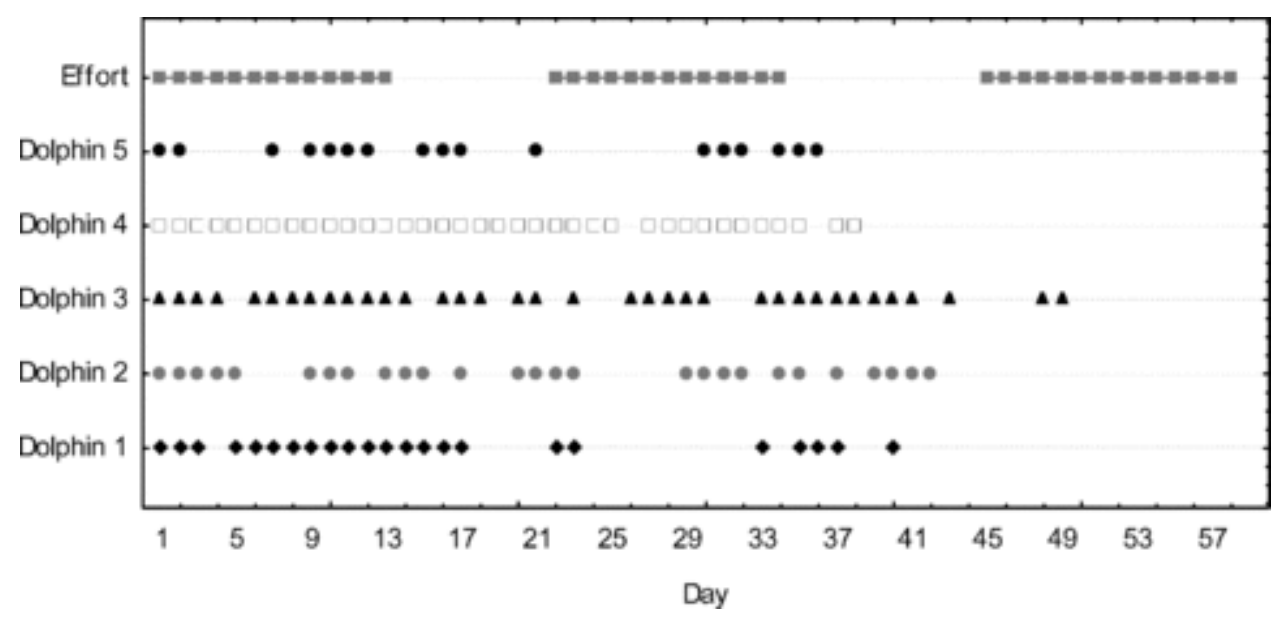

Figure 4. Diagram of the days on which satellite tagged Heaviside's dolphins were theoretically available to be captured photographically by the methods employed in this study. The effort (top) represents the temporal pattern of boat-based photo-ID data collection in 1999 although days not worked due to bad weather are not shown. 


\section{Discussion}

Ideally, the assumptions of mark-recapture estimates should be explicitly controlled for in the initial study design (e.g., Wilson et al. 1999). This study was designed to investigate individual dispersal patterns from a "point source" across a large spatial scale over 3 years, so the surveys were focused on maximizing area coverage and not on generating a population estimate. In retrospect, this study would have benefited from a longer field season or longer periods within the same areas to increase the recapture rate of animals, which would probably have increased the precision of our estimates and allowed us more flexibility to investigate biases including capture heterogeneity and survival rates.

In the absence of data from Heaviside's dolphins, a survival rate estimate for the closely related Commerson's dolphin (Cephalorhynchus commersonii) was used to compensate for inter-year mortality of marked animals. This estimate was based on beach-cast animals presumed to have been killed in the local gill net fishery (Lockyer et al. 1988). Although the level of human-induced mortality of Heaviside's dolphins is unknown, it is thought to be lower than that of either Commerson's (Lockyer et al. 1988) or Hector's dolphins (Cephalorhynchus hectori) (Slooten et al. 1992) because of the low density of human habitation and associated inshore fishing effort throughout the majority of their range (Elwen 2008) as well as the lack of overlap in either prey size (Sekiguchi et al. 1992) or distribution ${ }^{2}$ with the commercial hake fishery which targets larger fish offshore. Using the adult survival rate of Commerson's dolphin for correcting population estimates may therefore exaggerate the inter-year mortality of Heaviside's dolphins and so underestimate the population size.

Heaviside's dolphins were noted to vary considerably in their reaction toward the boat with some animals persistently following the boat to bowride it, while others were distinctly evasive. Such evasive behavior occurred more frequently in small groups (Elwen 2008) although any resulting sampling bias should be mediated by the high turnover of group membership in this species (Elwen 2008). However, if evasion or attraction is a stable characteristic of individual dolphins, it will not only introduce heterogeneity and bias the final estimate, but may imply that some animals are effectively uncatchable and will be excluded from the abundance estimate. When heterogeneity occurs, the CMP estimator can result in an underestimate of the true population size by as much as $30 \%$ (Carothers 1973).

Telemetry has shown that Heaviside's dolphins' use of the inshore environment varies considerably, with the five female dolphins being potentially available for photography on $39 \%-95 \%$ of their transmission days. True capture probabilities are likely to be much lower due to the limitations to daily survey length and an inability to find and subsequently capture good quality images of all individuals. If there were some part of the population that does not use the inshore study area at all, then it would remain uncatchable using this approach and be excluded from the abundance estimate. Since the tagged animals were all caught close to shore, they would effectively be part of such an "inshore cohort." Variation in capture probability is also likely in an alongshore 
direction due to site fidelity and the use of sub areas within home ranges (Elwen et al. 2006). If an animal's range only partially overlaps any study area it will reduce the amount of time it is available to be captured. These "edge effects" need to be specifically accounted for by knowledge of how distance from the study site edge affects capture probability (Boulanger and McLellan 2001). Given the high likelihood of heterogeneity in the capture probabilities of Heaviside's dolphins our population estimates are likely to be negatively biased.

Results from satellite telemetry also have implications for the choice of sampling frequency. Some mark-recapture studies of inshore delphinids use single days as the capture events in a modeling approach (e.g., Read et al. 2003, Chilvers and Corkeron 2003) on the assumption that each survey day is a random and representative sample of the population. This approach would be inappropriate for Heaviside's dolphins using our sampling methods as the satellite data indicated that their daily presence or absence inshore tended to be episodic over several days, and a sampling period of roughly a week might allow more representative sampling.

The low mark rate $(\theta)$ of Heaviside's dolphins is one of the biggest challenges in the application of mark-recapture techniques to this species. Values of $\theta$ in other studies are usually considerably higher than the $0.14-0.17$ used in this study and typically at least half the population is considered "marked" (0.53-0.75 in Stenella longirostris, Karczmarski et al. 2005; 0.56-0.68 in Tursiops truncatus, Wilson et al. 1999; 0.44 in Tursiops aduncus, Chilvers and Corkeron 2003; 0.63-0.78 in Orcaella heinsohni and 0.66-0.79 in Sousa chinensis, Parra et al. 2005). Even within the same genus, mark rates may be at least double that of Heaviside's dolphins, 0.33-0.74 in Cephalorhynchus eutropia (Heinrich 2006) and 0.36 in C. hectori (Bejder and Dawson 2001). The low mark rate in this population results in an extrapolation of roughly seven times and its accuracy is thus of considerable importance. Attempts to independently assess $\theta$ using estimates made by eye in the field were not entirely successful but were valuable in establishing a lower bound. Results suggest that field assessments underestimated the number of marked animals and estimation from photographs was considered more effective.

Values of $\theta$ varied across the study area as well as over time (at least in St Helena Bay where multiple samples were available). The majority of this variation is likely due to chance since only a very small proportion of the population was captured in each sample. It is not clear why the mark-rate in this species should be so low although their small triangular dorsal fins may be more robust or less susceptible to damage than the taller falcate fins of most dolphins. Collisions with boat hulls and propellers are known to result in scarring and injuries to dolphins that are useful for identification (Lockyer and Morris 1990) and the relatively low fishing effort and boat traffic throughout the study area may play a role in the overall low level of marks in this population. Reduction in mark rate with distance northward from Cape Town (by far the largest human habitation throughout the species range) suggests an anthropogenic origin for the marks. However, while commercial and recreational boat traffic is probably highest around Cape Town, the distribution of inshore fisheries (particularly set-nets) is 
centered away from Cape Town, in the St Helena Bay area (Elwen 2008). The observed patterns suggest that any anthropogenic influences on mark-rate are more likely due to interactions with boats than nets, but that most marks are likely to be natural in origin (i.e., the cause of interactions with other animals).

Where it is not possible to account for biases in analysis, it is at least preferable to know in which direction they are likely to occur. The data collected in this study suffered primarily from being too small and spread too thinly given the number of animals. The subsequent shortfall in population 'saturation' has had the principal effect of increasing variance in the resulting estimates and magnifying the role of capture heterogeneity. Biases were due principally to (1) violation of population closure due to natural mortality and population turnover between years, (2) a possible systematic bias in photographing distinctive vs. nondistinctive animals, and (3) heterogeneity of capture probability. We have made some efforts to account for (1) which would tend to inflate population estimates, and discussed (2) and (3) in greater detail above. Overall, given the known biases, our population estimates are likely to err on the low side, possibly substantially. Prior to this study there was no substantiated estimate of the abundance of Heaviside's dolphin in any part of its range and although variance is high in the estimates at all three spatial scales investigated, our results clearly show that Heaviside's dolphins are reasonably abundant within the area studied and number in the order of thousands of animals.

\section{Footnotes}

1 E. Cooch, and G. White, eds. Programme MARK: A gentle introduction. 5th edition. Available at http://www.phidot.org/software/mark/.

2 Personal communication from F. Le Clus, Marine and Coastal Management, Department of Environmental Affairs and Tourism, Private Bag X2, Rogge Bay 8012, South Africa, 2004.

\section{Literature cites}

BEJDER , L., S. DAWSON . 2001. Abundance, residency, and habitat utilisation of Hector's dolphins (Cephalorhynchus hectori) in Porpoise Bay, New Zealand. New Zealand Journal of Marine and Freshwater Research 35:277-287.

BEST , P. B., R. B. ABERNETHY . 1994. Heaviside's dolphin, Cephalorhynchus heavisidii (Gray, 1828). Pages 289-310, 415-416 in S. Ridgeway M. Harrison, eds. The handbook of marine mammals. Volume 6. Academic Press. New York, NY .

BOULANGER , J., B. MCLELLAN . 2001. Closure violation in DNA-based mark-recapture estimation of grizzly bear populations. Canadian Journal of Zoology 79:642-651. 
Burnham , K. P., D. R. Anderson, G. C. White , C. Brownie K. H. Pollock . 1987. Design and analysis methods for fish survival experiments based on releaserecapture. Monograph 5, American Fisheries Society, Bethesda, MD .

CAROTHERS , A. D. 1973. Capture recapture methods applied to a population with known parameters. Journal of Animal Ecology 42:125-146.

ChILvers , B. L., P. J. CORKERON . 2003. Abundance of Indo-Pacific bottlenose dolphins, Tursiops truncatus off Point Lookout, Queensland, Australia. Marine Mammal Science 19:85-95.

DAWSON, S. M. 1991. Incidental catch of Hector's dolphins in inshore gillnets. Marine Mammal Science 7:283-295.

DURBAN , J. W., D. A. ELSTON . 2005. Mark-recapture with occasion and individual effects: Abundance estimation through Bayesian model selection in a fixed dimensional parameter space. Journal of Agricultural, Biological, and Environmental Statistics 10:291-305.

ELWEN, S. H. 2008. The distribution, movements and abundance of Heaviside's dolphins in the nearshore waters of the Western Cape, South Africa. Ph.D. dissertation, University of Pretoria, Pretoria, South Africa . 211 pp.

Elwen, S. H., M. A. MeŸer , P. B. Best , P. G. H. Kotze , M. Thornton S. SWANSON . 2006. Range and movements of female Heaviside's dolphins Cephalorhynchus heavisidii as determined by satellite telemetry. Journal of Mammalogy 87:866-877.

FINDLAY , K. P., P. B. BEST , G. J. B. ROSS V. G. COCKROFT . 1992. The distribution of small odontocete cetaceans off the coast of South Africa and Namibia. South African Journal of Marine Science 12:237-270.

FRIDAY , N., T. SMITH , P. STEVICK J. ALLEN . 2000. Measurement of photographic quality and individual distinctiveness for the photographic identification of humpback whales, Megaptera novaeangliae. Marine Mammal Science 16:355-374.

GOWANS , S., H. WHITEHEAD . 2001. Photographic identification of northern bottlenose whales (Hyperoodon ampullatus): Sources of heterogeneity. Marine Mammal Science 17:76-93.

HAMMOND , P. S. 1986. Estimating the size of naturally marked whale populations using capture-recapture techniques. Report of the International Whaling Commission (Special Issue 8):253-282.

HEINRICH , S. 2006. Ecology of Chilean dolphins and Peale's dolphins at Isla Chiloé, southern Chile. Ph.D. dissertation, University of St Andrews, Scotland, U.K. 258 pp. 
IÑígueZ , M. A., M. HeVia , C. GASPARrou , A. L. TOMSIN E. R. SECCHI . 2003. Preliminary estimate of incidental mortality of Commerson's dolphins (Cephalorhynchus commersonii) in an artisanal setnet fishery in La Angelina beach and Ría Gallegos, Santa Cruz, Argentina. Latin American Journal of Aquatic Mammals 2:87-94.

KARCZMARSKI , L., B. WÜRSIG , G. GAILEY , K. W. LARSON C. VANDERLIP . 2005. Spinner dolphins in a remote Hawaiian atoll: Social grouping and population structure. Behavioral Ecology 16:675-685.

LOCKYER , C. H. R. J. MORRIS . 1990. Some observations on wound healing and persistence of scars in Tursiops truncatus. Report of the International Whaling Commission (Special Issue 12):113-118.

LOCKYER , C., R. N. P. GOODALl A. R. GALEAZZI . 1988. Age and body length characteristics of Cephalorhynchus commersonii from incidentally caught specimens off Tierra del Fuego. Report of the International Whaling Commission (Special Issue 9):103-118.

PARRA , G. J., P. J. CORKERON H. MARSH . 2005. Population sizes, site fidelity and residence patterns of Australian snubfin and Indo-Pacific humpback dolphins: Implications for conservation. Biological Conservation 129:167-180.

READ , A. J., K.W. URIAN , B. WILSON D. M. WAPLES . 2003. Abundance of bottlenose dolphins in the bays, sounds, and estuaries of North Carolina. Marine Mammal Science 19:59-73.

SEBER, G. A. F. 1982. The estimation of animal abundance and related parameters. 2nd edition. Griffin, London, U.K.

SEKIGUCHI , K. 1994. Studies on feeding habits and dietary analytical methods for the smaller odontocete species along the southern African coast. Ph.D. thesis, University of Pretoria, Pretoria, South Africa . 259 pp.

SEKIGUCHI , K., N. T. W. KLAGES P. B. BEST . 1992. Comparative analysis of the diets of smaller odontocete cetaceans along the coast of southern Africa. South African Journal of Marine Science 12:846-861.

SLOOTEN , E., S. M. DAWSON F. LAD . 1992. Survival rates of photographically identified Hector's dolphins from 1984 to 1988. Marine Mammal Science 8:327-343.

Stevick, P. S., P. J. PAlsbøll, T. D. SMith , M. V. BRAVington P. S. HAMmOND . 2001. Errors in identification using natural markings: Rates, sources, and effects on capture-recapture estimates of abundance. Canadian Journal of Fisheries and Aquatic Sciences 58:1861-1870. 
White, G. C., D. R. ANDERSON, K. P. BuRnham D. L. OTIS . 1982. Capturerecapture and removal methods for sampling closed populations. LA-8787-NERP, Los Alamos National Laboratory, Los Alamos , NM .

WILSON , B., P. S. HAMMOND P. M. THOMPSON . 1999. Estimating size and assessing trends in a coastal bottlenose dolphin population. Ecological Applications 9:288-300. 